\title{
CELESTINA, AUTO I: "MINERUA CON EL CAN"
}

El texto de la Comedia de Calisto y Melibea, en la edición de 1499, presenta - por lo menos en algún lugar-varias groseras erratas. Menéndez Pidal ha demostrado, de manera muy convincente, que las palabras "Eras y Crato médicos" (auto I) deben leerse "Erasístrato, médico", y que el ininteligible "piedad de silencio" (ibid.) es errata por "piedad de Seleuco"1. En el presente trabajo intento probar que en vez de "Minerua con el can", palabras que se encuentran en el mismo auto I (ed. Cejador, vol. I, pág. 45), hay que leer "Minerua con Vulcán".

Sempronio está reprendiendo a Calisto porque somete "la dignidad del hombre a la imperfección de la flaca mujer", y para corroborar sus dichos aduce ejemplos de la Antigüedad:

Dixe que tú, que tienes más coraçón que Nembrot ni Alexandre, desesperas de alcançar vna muger, muchas de las quales, en grandes estados constituýdas, se sometieron a los pechos $\mathrm{e}$ resollos de viles azemileros e otras a brutos animales. ¿No has leýdo de Pasife con el toro, de Minerua con el can?

La nota de Cejador a este pasaje (sobre aquello quod ad coitum iumentorum concernit) explica satisfactoriamente el caso de Pasífae - por lo demás, muy conocido-, pero, como es natural, no nos dice qué aventura tuvo Minerva "con el can". Tampoco hay alusión a ello en el Ausführliches Lexicon der griechischen und römischen Mythologie de W. H. Roscher. En el Oxford classical dictionary, s. v. Athena, leemos que a esta diosa siempre se la tuvo por virgen ("she is regularly regarded as virgin"). Si prescindimos de las versiones preliterarias del mito de Erictonio ${ }^{2}$ (sobre las cuales volveremos

1 Ramón Menéndez Pidal, Antologia de prosistas castellanos, Madrid, 1920, págs. 69-7o, nota 1.

${ }^{2}$ Véase $P W R E$, s. v. Erichthonius: "El Erictonio ático es personaje secundario con respecto a Erecteo. El poeta de la Danais... menciona a Erictonio como fruto de la tierra; lo mismo hace Pindaro... También de Erecteo -transformado luego en Erictonio- se dice que brotó de la tierra, del campo de cultivo, y esto, al parecer, en pugna con otra versión que relacionaba más estrechamente a Erecteo con Atena (cf. German., Arat., 158). Esta mismá pugna se expresa de manera clara en Eurípides $(I o n, 270) \ldots$ De ello puede deducirse que a Erictonio 
después), todo justificaba la creencia expresada por Diego de San Pedro en su Cárcel de amor (una de las fuentes de la Celestina, como es bien sabido): "Palas o Minerua, vista primeramente cerca de la laguna de Tritonio, nueua inuentora de muchos oficios mugeriles y avn de algunos de los hombres, virgen biuió y acabó"3. En el Ión de Eurípides ya se defiende a Minerva contra los rumores que, evidentemente, la bacían aparecer como madre de Erictonio.

Se cuentan, por supuesto, varias Minervas. Las mencionamos aquí sólo para tener una idea completa, puesto que lo que nos interesa es sólo la leyenda de Erictonio. Cicerón dice (De natura deorum, III, 57) : "Vulcani item complures: primus Caelo natus, ex quo et Minerua Apollinem eum, cuius in tutela Athenas antiqui historici esse uoluerunt"; y en el mismo libro, capítulo 59, hablando de las varias Minervas: "... prima, quam Apollinis matrem supra diximus ...; tertia, illa, quam Ioue generatam supra diximus". Y Boccaccio, Genealogia deorum gentilium, V, 48: "Nec ea fuit hec quam ueteres uirginem et sterilem asseruere, quin imo, ut idem dicit Tullius, ex Vulcano... Apollinem ... peperit" (cf. II, 3; III, 18, 19; XII, 71). Ya los Padres de la Iglesia se habían dado cuenta de esa multiplicidad de Minervas. En el Index mythologicus de la Patrologia Latina leemos "Mineruae quinque"; pero al recorrer los pasajes respectivos comprobamos que nunca hay la menor alusión a una posible o concebible Liebesverbindung de Minerva (cualquiera de ellas) con un can. Sin embargo, si seguimos la pista que nos da Eurípides $^{4}$ e investigamos las relaciones de Atena-Minerva con HefestoVulcano, sobre todo en lo que atañe al nacimiento de Erictonios, podremos resolver el problema.

Ante todo, el que Minerva apareciera como inventora y patrocinadora de diversas artes manuales, y su título Ergane, 'la Trabajadora', hicieron que sus funciones se confundieran, en cierta medida, con las de Hefesto-Vulcano, lo cual explica la conexión mítica entre ambos (cf. el Oxford classical dictionary, loc. cit.).

Hefesto es el esposo de Atena, es decir, de la diosa de la ciudad baja, patrona de los alfareros ... La leyenda de la unión amorosa es ... más antigua. Una estela ática en barro, del siglo $\mathrm{v}$, presenta a Atena y a Hefesto en presencia de Eros ... Cicerón (De natura deorum, III, 55 y 57 ) menciona a Apolo Pátroo como

se le tenía también por verdadero hijo carnal de Atena. No se menciona a su padre".

${ }^{3}$ Origenes de la novela, tomo. II (NBAE, vol. VII), Madrid, 1907, pág. $27 b$.

* Véase supra, nota 2.

${ }^{5}$ Sobre el mito del nacimiento de Erictonio se encontrará una buena bibliografía en la edición y traducción de la Biblioteca de Apolodoko por Sir James George Frazer, Loeb Classical Library, London-New York, 1921, vol. II, pág. 9o, nota 1. 
hijo de ambos ... No tenemos datos más precisos sobre el mito de la unión de Hefesto y Atena, el cual, según parece, pasó de Jonia a Atenas... Tampoco podemos decir si en la versión primitiva de la leyenda se aludía ya a un fruto de esta unión, o si sólo más tarde, en Atenas, ocupa ese lugar Erecteo, transformado en tiempo de Pisístrato bajo el nombre que le daba la poesía épica. En todo caso, el mito refleja la oposición entre el pueblo de la ciudad baja y la nobleza dominante. Esa historia amorosa era inconveniente para la diosà de la Acrópolis; había que reivindicar su fama de virginidad. Por eso, con múltiples motivaciones y variaciones, se creó la desagradable historia del origen de Erictonio, nacido del semen que Hefesto derramó en tierra: así se conciliaban las dos cosas: por una parte la leyenda de Erictonio como fruto de la tierra y los cuidados maternales con que lo recibió Atena (mütterliche Pflege durch Athena), y por otra parte la tradición del matrimonio de Atena y Hefesto ${ }^{6}$.

La versión reivindicadora de la honra de Minerva aparece en gran número de autores -Higino, Servio el Gramático, etc.-, y la encontramos en esta forma en San Agustín:

Erichthonii regis Atheniensium, cuius [sic] nouissimis annis Iesus Naue [i. e., Natiuitate] mortuus reperitur, Vulcanus et Minerua parentes fuisse dicuntur. Sed quoniam Mineruam uir. ginem uolunt, in amborum contentione Vulcanum commotum effudisse aiunt semen in terram, atque inde homini nato ob eam

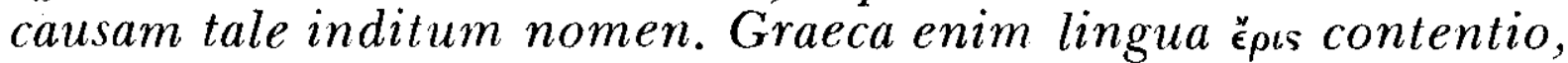
et $\chi \theta \dot{\omega} v$ terra est; ex quibus duobus compositum est Erichthonius $^{\top}$.

En su edición del De ciuitate Dei, Juan Luis Vives pone la siguiente nota al pasaje anterior:

Erichthonii regis Atheniensium ..., cuius patrem mortalium nullum fuisse putant: progenitum uero ex Vulcano et terra. Sed quoniam Mineruam uirginem uolunt, Iuppiter quum Mineruam, quam in capite gerebat, parturiret, implorata Vulcani securi, iussit sibi caput findi, unde subito orta est Minerua uirgo armata, saltitans. Hanc in mercedem illius uelut obstetricatus, seu quod arma Ioui fecisset...., coniugem sibi Vulcanus deposcit, eamque rem totam Iuppiter arbitrio detulit puellae, quae uiro negauit se ulli nupturam; cumque permissu Iouis Vulcanus ui eam uellet cogere, excitata natura, semen effudit in terram, quod pudibunda Pallas terra operuit, unde Erichthonius est natus .

- PWRE, art. cit.

` De ciuitate Dei, XVIII, xII, en PL, vol. XLI, col. 570 .

8 Edición de Basilea, 1542 , col. 1026. 
Hasta aquí, la reputación de Minerva está sin mancha, pues defendió su virginidad, y con buena fortuna. Pero, lo mismo que en el caso de Lucrecia ${ }^{9}$, parece que en algunos había aún lugar a dudas; lo que les daba asidero era la leyenda de los "cuidados maternales" que Minerva prodigó a Erictonio. Apolodoro (Biblioteca, III, xIv, 6), después de contar cómo fué procreado éste, agrega: "Atena lo crió a escondidas de los demás dioses, con el deseo de hacerlo inmortal; y, después de ponerlo en un cofre, lo encomendó a Pándroso, hija de Cécrope..." (en otras versiones, a las hijas de Cécrope). ¿Por qué ese maternal interés? ¿Por qué tanto secreto? En el Index mythologicus de la Patrologia Latina encontramos esta indicación: "Mineruae uirginitas suspecta", y, siguiendo la referencia a Lactancio, leemos una interpretación desfavorable a la diosa en un capítulo intitulado "De deorum aerumnis et turpitudinibus":

Sed ne quidem illae uirgines [Minerva y Diana] illibatam castitatem seruare potuerunt. Unde enim putemus Erichthonium esse natum? an ex terra, ut poetae uideri uolunt? At res ipsa clamat. Nam cum Vulcanus diis arma fecisset, eique Iupiter optionem dedisset praemii quod uellet postulandi, iurassetque, ut solebat, per infernam paludem se nihil negaturum, tum faber claudus Mineruae nuptiis postulauit. Hic Iupiter Opt. Max., tanta religione constrictus, abnuere non potuit; Mineruam tamen monuit repugnare pudicitiamque defendere. Tum in illa colluctione Vulcanum in terram profudisse aiunt semen, unde sit Erichthonius natus... Cur igitur uirgo eum puerum cum dracone et obsignatum tribus uirginibus Cecropidis commendauit? Euidens, ut opinor, incestum, quod nullo modo possit colorari ${ }^{10}$.

Incestum, porque Minerva y Vulcano eran hijos de Júpiter. $M i$ neruae uirginitas suspecta. Mütterliche Pflege durch Athena. ¿No has leýdo de Minerua con el can? Vulcano, claro está, no era un "vil azemilero", pero sí un herrero afeado por un defecto físico -faber claudus-, mal partido para una diosa como Minerva, "en grande estado constituýda". No era el más limpio de los amantes, sino un armero, un "resollador" como la forja de su herrería.

Fernando de Rojas tenía cierta familiaridad con los Padres de la Iglesia. En ese mismo auto I utiliza el comentario de Orígenes In Matthaeum y los Sermones de San Pedro Crisólogo, como ha demostrado Castro Guisasola. Pero su idea de la uirginitas suspecta de Minerva no tuvo que tomarla necesariamente de Lactancio. La sospecha del stuprum Mineruae pudo haberle quedado por la lectura de una

•Véase Joseph E. Gillet, “Lucrecia - necia”, en $H R$, XV, 1947, págs. 120-196.

10 Lactancio, en $P L$, vol. VI, cols. 207-209. 
afirmación tan sencilla e incompleta como la de Servio, In Virgilii Georgicon, I, 205 (cf. también III, 113): "Sane nonnulli hunc aurigam Myrtilum, quem Pelops occidit, accipiunt, uel certe Erichthonium, qui natus est ex semine Vulcani, quod, dum stuprum Mineruae inferre conaretur, fudit in terram".

Cualquiera que sea la fuente de Rojas, se puede reconstruir fácilmente el origen del error textual de la Celestina: el manuscrito que el impresor tuvo en sus manos decía: "Minerua con uulcan", quizá con un espacio entre la $l$ y la $c$ : "uul can". El impresor - cosa muy excusable- imaginó un paralelo entre esto y "con el toro", y así interpretó "con el can". Pero hay que observar que Rojas quiso presentar sus categorías en orden inverso, en un quiasmo: hombre indigno : bruto animal :: toro : Vulcán ${ }^{11}$.

University of Pennsylvania.

OTIS H. Green

${ }^{11}$ Sobre la historia de la "bestialidad" y la idea de los híbridos humanos véase Conway ZIRkLe, The beginnings of plant hybridization, Philadelphia, 1935 , cap. I ("The earliest descriptions of hybrids"), en especial las págs. 42 y sigs. No sć qué cosa quiso decir Cristóbal Suárez de Figueroa en el siguiente pasaje de su Plaza universal, Madrid, 1615 (Discurso LXXI, "De las rameras y de sus sequazes", fol. $272 \mathrm{v}^{\circ}$ ): "Pregunto, ¿a qué efeto fueron inuentadas por ellas dulces risas, piadosas lágrimas, palabras suaues y regaladas promessas sino para conquistar las almas, de forma que estando fuera de sí digan o escriuan ser tales risas de Venus, tales lágrimas de Dido por Eneas, aquellos llantos de Eco por Narcisso, aquellas palabras de Palas enamorada y aquellas promessas que hizo Iuno a Paris?" 